\title{
Drug interaction between a selective serotonin reuptake inhibitor and a triptan leading to serotonin toxicity: a case report and review of the literature
}

Gilbert Jin ${ }^{*}(\mathbb{D}$ and Philip Stokes

\begin{abstract}
Background: Serotonin toxicity is a known side effect of selective serotonin reuptake inhibitors and has previously also been described as a possible side effect of 5-hydroxytryptamine receptor agonist (triptan) medications. However, the literature is conflicted about the risk of developing serotonin toxicity as a result of drug interaction between selective serotonin reuptake inhibitors and triptans.
\end{abstract}

Case presentation: A 30-year-old Caucasian woman with a history of depression on regular fluvoxamine presented to the emergency department with right-sided facial and lower limb twitching. The patient had recently been prescribed sumatriptan for migraines and had taken her first ever dose shortly prior to the onset of symptoms. She was tachycardic, diaphoretic, and hypertonic on initial assessment with bilateral lower limb and ocular clonus. Electrocardiogram showed sinus tachycardia with QT interval under the treatment interval, and pathology and imaging findings were unremarkable. Her symptoms improved with supportive management and cyproheptadine.

Conclusions: This patient's presentation fulfilled both Sternbach and Hunter criteria for serotonin toxicity, illustrating a potential case of serotonin toxicity as a result of drug interaction between a selective serotonin reuptake inhibitor and a triptan.

Keywords: Serotonin toxicity, Serotonin reuptake inhibitors, Serotonin 5-HT1 receptor agonists, Triptans, Adverse effects, Drug interaction

\section{Background}

As prescriptions of serotonergic medications have increased in recent years, serotonin toxicity has become an increasingly prevalent phenomenon [1]. Selective serotonin reuptake inhibitor (SSRI) and selective norepinephrine reuptake inhibitor (SNRI) medications are commonly prescribed for management of mood and anxiety disorders, and are frequently implicated in presentations of serotonin toxicity [2].

${ }^{*}$ Correspondence: gilbertjin92@gmail.com

Redcliffe Hospital, Anzac Avenue, Redcliffe, QLD 4020, Australia 5-hydroxytryptamine receptor agonists, also known as serotonin receptor agonists or triptans, are commonly prescribed for the management of migraine. They are commonly coprescribed with SSRIs and SNRIs and have been previously implicated in cases of serotonin toxicity as a result of drug interaction, although such cases are rare [3].

Serotonin toxicity remains a clinical diagnosis, and can be a challenging one to make. Due to its wide spectrum of severity and easily overlooked symptoms, diagnosis can often be missed, especially if the patient does not present with a clear history of overdose [2]. It can also occur as a result of drug interaction, and should be an important original author(s) and the source, provide a link to the Creative Commons licence, and indicate if changes were made. The images or other third party material in this article are included in the article's Creative Commons licence, unless indicated otherwise in a credit line to the material. If material is not included in the article's Creative Commons licence and your intended use is not permitted by statutory regulation or exceeds the permitted use, you will need to obtain permission directly from the copyright holder. To view a copy of this licence, visit http://creativecommons.org/licenses/by/4.0/. The Creative Commons Public Domain Dedication waiver (http://creativeco mmons.org/publicdomain/zero/1.0/) applies to the data made available in this article, unless otherwise stated in a credit line to the data. 
differential diagnosis in any patient known to be taking serotonergic medications.

This case report aims to discuss a case of drug interaction between a triptan and an SSRI leading to a suspected case of serotonin toxicity.

\section{Case presentation}

A 30-year-old Caucasian woman presented to the emergency department (ED) with right-sided facial and lower limb twitching. She also reported a headache for the past 5 days, similar to her previous migraines. She had taken a dose of sumatriptan approximately 6-8 hours prior to presentation to alleviate the pain. This medication had been newly prescribed by her general practitioner with no history of prior use by the patient. Shortly after taking the sumatriptan, the patient developed gradually worsening right-sided facial and lower limb twitching, with discomfort in the right arm and right leg and associated difficulty with speech. She had taken paracetamol at home prior to this event and denied ingestion of any other medications, including prescription medications as well as herbal and over-the-counter supplements. She also denied any recent alcohol or illicit drug use.

Her past medical history was significant for longstanding depression for which she was on regular fluvoxamine $100 \mathrm{mg}$ once daily, as well as hemiplegic migraines (usually managed with simple analgesia), endometriosis, and paroxysmal supraventricular tachycardia. She denied any recent changes in her fluvoxamine dose. Her other regular medications included pregabalin and tranexamic acid, which she did not take on the day of presentation. She had no significant family history and denied regular alcohol or drug use. She denied any regular smoking history.

On initial assessment, she had a heart rate of 120 beats per minute and blood pressure of $144 / 96 \mathrm{mmHg}$, but otherwise normal vital signs and a Glasgow Coma Scale (GCS) score of 15 . Temperature was normal at $36.5{ }^{\circ} \mathrm{C}$. She had notably diaphoretic palms and a resting tremor in her right arm and leg. Initial ophthalmic assessment showed bilaterally sluggish and dilated pupils with ocular clonus. She had bilateral lower limb hypertonicity and hyperreflexia with six to seven beats of inducible clonus in both ankles. Power and sensation were normal in all four limbs, and full neurological examination was otherwise unremarkable. There were no other significant findings on physical examination.

Initial electrocardiogram (ECG) showed sinus tachycardia with a QT interval below the treatment line on QT nomogram. Full blood count, electrolytes, liver function tests, and serum beta human chorionic gonadotropin (HCG) were unremarkable. Computed tomography (CT) scan of her head showed no evidence of intracranial lesion and was grossly normal for age.
Based on her clinical presentation and history of SSRI use, the patient was diagnosed with serotonin toxicity. Differential diagnoses at the time included atypical focal seizure, alternate drug toxidrome (such as anticholinergic or sympathomimetic toxicity) or withdrawal phenomenon.

The patient was placed on telemetry and was given supportive treatment with slow intravenous fluids as well as a dose of $12 \mathrm{mg}$ oral cyproheptadine, a potent antihistamine and serotonin antagonist. Her fluvoxamine and sumatriptan were withheld, and she was kept in the ED short-stay unit overnight for a prolonged period of observation. Periodic reviews throughout her admission showed an incremental improvement in her serotonergic symptoms, with improvement in her motor symptoms and agitation, as well as her ocular and lower limb clonus.

On her morning review, the patient had returned to baseline with resolution of her clonus and tremor and a completely normal repeat neurological examination, aside from some mild residual lower limb hyperreflexia. She was discharged home with instructions to withhold her fluvoxamine for 24 hours and to avoid taking any further concomitant triptan medications in the future, to be followed up by her usual general practitioner.

\section{Discussion and conclusions}

In summary, this case describes a 30-year-old woman who presented with a likely case of serotonin toxicity as a result of drug interaction between her regular SSRI and a newly prescribed triptan medication. While there have been scattered case reports of this in the literature, very few have described a case of serotonin toxicity as a direct result of drug interaction that fulfills formal diagnostic criteria.

Serotonin toxicity is a clinical toxidrome characterized by a triad of autonomic hyperactivity, neuromuscular excitation, and altered mental state [2], and can be a potentially life-threatening side effect of serotonergic medications if left untreated [1]. It is a clinical diagnosis and can have a wide spectrum of symptoms and severity, and as such is often underrecognized. In recent years, a number of diagnostic criteria have been proposed to provide a more objective basis for diagnosis. The two most commonly used diagnostic criteria in current clinical practice are the Sternbach and Hunter criteria, as presented in Table $1[4,5]$.

Management of serotonin toxicity is typically supportive in nature, in addition to withdrawal of serotonergic medications, but can differ depending on the severity of presentation. In severe cases, treatment may necessitate airway and cardiorespiratory support, as well as muscle paralysis and active cooling to prevent hyperthermia and muscle rigidity. Mild-to-moderate cases often require 
Table 1 Hunter and Sternbach criteria for serotonin toxicity

\begin{tabular}{|c|c|}
\hline \multicolumn{2}{|l|}{ Hunter and Sternbach criteria for serotonin toxicity } \\
\hline $\begin{array}{l}\text { Hunter criteria [4] } \\
\text { One or more of the following in the presence of a serotonergic drug: } \\
\text { Hypertonia } \\
\text { Inducible clonus and agitation or diaphoresis } \\
\text { Ocular clonus and agitation or diaphoresis } \\
\text { Spontaneous clonus } \\
\text { Tremor and hyperreflexia } \\
\text { Temperature }>38^{\circ} \mathrm{C} \text { and ocular or inducible clonus }\end{array}$ & $\begin{array}{l}\text { Sternbach criteria [5] } \\
\text { Addition or increase in dose of serotonergic agent } \\
\text { No commencement or increase in dose of neuroleptic treatment prior to onset } \\
\text { of symptoms } \\
\text { At least three of the following: } \\
\text { Agitation } \\
\text { Diaphoresis } \\
\text { Diarrhea } \\
\text { Fever } \\
\text { Hyperreflexia } \\
\text { Incoordination } \\
\text { Myoclonus } \\
\text { Shivering } \\
\text { Tremor }\end{array}$ \\
\hline
\end{tabular}

only a period of observation and symptomatic management with benzodiazepines or cyproheptadine, and antiemetics [2].

In 2006, the United States Food and Drug Administration (FDA) issued an alert regarding a potential risk of developing serotonin toxicity as a result of concomitant use of SSRI or SNRI antidepressants with triptans [6]. Since then, the literature has been largely critical of the FDA's position. Subsequent analyses of the case reports on which the FDA alert was based have found that a number of them did not actually meet diagnostic criteria for serotonin toxicity [3, 7]. A position paper from the American Headache Society in 2010 found that the quality of evidence supporting the FDA's recommendation was poor and that there was insufficient evidence to support limiting the coprescription of SSRIs/SNRIs and triptans [8].

A subsequent retrospective database study of 19,017 patients who were coprescribed triptans and SSRIs/ SNRIs found only 7 patients who met diagnostic criteria for serotonin toxicity, of which only 4 met both Sternbach and Hunter criteria. It concluded that the risk of developing serotonin toxicity from concomitant administration of SSRIs/SNRIs and triptans was low and recommended that the FDA advisory be reconsidered [9]. It has been postulated that the reason for this may lie in the affinity of triptan medications to certain serotonin receptor subtypes, with a higher affinity to serotonin $1 \mathrm{~B}$ and $1 \mathrm{D}$ receptors. In contrast, emerging evidence suggests that serotonin syndrome is more heavily mediated by serotonin $1 \mathrm{~A}$ or $2 \mathrm{~A}$ receptors, for which triptans have only a low affinity [9].

However, as this case shows, while the risk of such drug interaction is low, it is not absent. The patient in this case had a likely diagnosis of serotonin toxicity as a result of drug interaction between her fluvoxamine and sumatriptan. While in ideal circumstances she would have had formal laboratory drug testing to confirm the drugs of exposure and to exclude any confounding agents, these tests are simply not realistic to perform in an emergency department environment. She did, however, satisfy clinical criteria for serotonin toxicity, which remains the mainstay of diagnosis to guide patient management. She met both Sternbach and Hunter criteria for serotonin toxicity, presenting with agitation, tremor, hyperreflexia, and both spontaneous and inducible clonus, including limb and ocular clonus. Further supporting the diagnosis were her tachycardia and mydriasis, as well as the complete resolution of her symptoms with administration of cyproheptadine, a specific histamine antagonist.

In conclusion, this case report describes a case of probable serotonin toxicity as a consequence of coadministration of an SSRI and triptan. Clinicians should be aware of the risk and counsel patients on the potential for drug interaction, and should also have a clinical index of suspicion in patients presenting with serotonergic symptoms who are on such medications, even without a history of overdose. Recognition of serotonin toxicity is key in managing these patients in an appropriate and timely fashion.

\section{Abbreviations \\ SSRI: Selective serotonin reuptake inhibitor; SNRI: Selective norepinephrine reuptake inhibitor; ED: Emergency department; GCS: Glasgow Coma Scale; ECG: Electrocardiogram; CT: Computed tomography; FDA: Food and Drug Administration; beta HCG: Beta human chorionic gonadotropin.}

\section{Acknowledgements}

Not applicable.

\section{Authors' contributions}

GJ was the treating clinician and primary author of the manuscript. PS provided editorial support, guidance and was involved in final approval of the manuscript. Both authors read and approved the final manuscript.

\section{Funding}

No funding was used in the preparation of this manuscript. 
Availability of data and materials

Not applicable.

\section{Declarations}

Ethics approval and consent to participate

Not applicable.

\section{Consent for publication}

Written informed consent was obtained from the patient for publication of this case report and any accompanying images. A copy of the written consent is available for review by the Editor-in-Chief of this journal.

\section{Competing interests}

The authors declare that they have no competing interests.

Received: 22 January 2021 Accepted: 7 June 2021

Published online: 26 July 2021

\section{References}

1. Boyer EW, Shannon M. The serotonin syndrome. N Engl J Med. 2005:352(11):1112-20.

2. Isbister GK, Buckley NA, Whyte IM. Serotonin toxicity: a practical approach to diagnosis and treatment. Med J Aust. 2007;187(6):361-5.

3. Evans RW. The FDA alert on serotonin syndrome with combined use of SSRIs or SNRIs and Triptans: an analysis of the 29 case reports. Medscape Gen Med. 2007;9(3):48.
4. Dunkley EJ, Isbister GK, Sibbritt D, Dawson AH, Whyte IM. The Hunter Serotonin Toxicity Criteria: simple and accurate diagnostic decision rules for serotonin toxicity. QJM Mon J Assoc Physicians. 2003;96(9):635-42.

5. Sternbach $\mathrm{H}$. The serotonin syndrome. Am J Psychiatry. 1991;148(6):705-13.

6. US Food and Drug Administration. Information for healthcare professionals: selective serotonin reuptake inhibitors (SSRIs), selective serotoninnorepinephrine reuptake inhibitors (SNRIs), 5-hydroxytryptamine receptor agonists (Triptans). 2006. https://wayback.archive-it.org/7993/20170 722190712/https://www.fda.gov/Drugs/DrugSafety/PostmarketDrugS afetylnformationforPatientsandProviders/DrugSafetyInformationforH eathcareProfessionals/ucm085845.htm. Accessed Dec 2019.

7. Wenzel RG, Tepper S, Korab WE, Freitag F. Serotonin syndrome risks when combining SSRI/SNRI drugs and triptans: is the FDA's alert warranted? Ann Pharmacother. 2008;42(11):1692-6.

8. Evans RW, Tepper SJ, Shapiro RE, Sun-Edelstein C, Tietjen GE. The FDA alert on serotonin syndrome with use of triptans combined with selective serotonin reuptake inhibitors or selective serotonin-norepinephrine reuptake inhibitors: American Headache Society position paper. Headache. 2010;50(6):1089-99.

9. Orlova Y, Rizzoli P, Loder E. Association of coprescription of triptan antimigraine drugs and selective serotonin reuptake inhibitor or selective norepinephrine reuptake inhibitor antidepressants with serotonin syndrome. JAMA Neurol. 2018;75(5):566-72.

\section{Publisher's Note}

Springer Nature remains neutral with regard to jurisdictional claims in published maps and institutional affiliations.
Ready to submit your research? Choose BMC and benefit from:

- fast, convenient online submission

- thorough peer review by experienced researchers in your field

- rapid publication on acceptance

- support for research data, including large and complex data types

- gold Open Access which fosters wider collaboration and increased citations

- maximum visibility for your research: over $100 \mathrm{M}$ website views per year

At BMC, research is always in progress.

Learn more biomedcentral.com/submissions 